read imaging. Only patients with complete data on diagnosis and imaging at baseline and 2 years were included.

Patients were labelled with a consistent axSpA diagnosis if they had a diagnosis of axSpA at baseline and at two-year follow-up. Those patients whose diagnosis switched from axSpA to no axSpA; or from no axSpA to axSpA were labelled inconsistent axSpA diagnosis.

Results: Over two years, in 295 patients with CBP the diagnostic consistency rate was $84 \%$, of whom 184 patients $(62 \%)$ had a diagnosis axSpA and $66(22 \%)$ a diagnosis no axSpA at both timepoints. 26 patients changed from axSpA to no axSpA (9\%) and 19 patients from no axSpA to axSpA (7\%).

The patients who only had an axSpA diagnosis at baseline were more often male and less often HLA-B27 positive compared to the other two groups (Table). Furthermore, both groups with an inconsistent diagnosis had fewer SpA features and a lower level of confidence of the diagnosis (LoC) compared to the group with a consistent diagnosis of axSpA, especially at baseline.

Table 1. Characteristics at baseline and 2-year follow-up of the group with a consistent axSpA diagnosis over 2 years and the groups whose diagnosis (axSpA/no axSpA) changed

\begin{tabular}{|c|c|c|c|c|c|c|}
\hline & \multicolumn{2}{|c|}{$\begin{array}{l}\text { Consistent diag- } \\
\text { nosis axSpA } \\
\text { AxSpA at } \\
\text { baseline and 2yrs } \\
(N=184) \\
\text { Baseline 2-year }\end{array}$} & \multicolumn{2}{|c|}{$\begin{array}{c}\text { Inconsistent } \\
\text { diagnosis } \\
\text { AxSpA at } \\
\text { baseline only } \\
(N=26) \\
\text { Baseline 2-year }\end{array}$} & \multicolumn{2}{|c|}{$\begin{array}{c}\text { Inconsistent } \\
\text { diagnosis } \\
\text { AxSpA at } \\
\text { 2yrs only } \\
(N=19) \\
\text { Baseline 2-year }\end{array}$} \\
\hline Female & $45 \%$ & & $15 \%$ & & $42 \%$ & \\
\hline Inflammatory Back Pain & $69 \%$ & $74 \%$ & $69 \%$ & $77 \%$ & $68 \%$ & $84 \%$ \\
\hline HLA-B27 positive & $75 \%$ & $75 \%$ & $27 \%$ & $27 \%$ & $68 \%$ & $68 \%$ \\
\hline Sacroiliitis radiographs* & $27 \%$ & $38 \%$ & $0 \%$ & $0 \%$ & $5 \%$ & $5 \%$ \\
\hline Sacroiliitis MRI ${ }^{*}$ & $69 \%$ & $81 \%$ & $23 \%$ & $27 \%$ & $5 \%$ & $21 \%$ \\
\hline Number of SpA features, mean (SD) & $5(2)$ & $7(2)$ & $3(1)$ & $5(2)$ & $3(1)$ & $5(1)$ \\
\hline $\begin{array}{l}\text { LoC diagnosis axSpA/no axSpA, } \\
\text { mean (SD) }\end{array}$ & $8.1(2.0)$ & $8.6(1.8)$ & $5.8(1.7)$ & $7.5(1.9)$ & $5.6(2.2)$ & $6.1(2.3)$ \\
\hline
\end{tabular}

* Based on local reading axSpA, axial Spondyloarthritis; HLA-B27, Human Leucocyte Antigen B27; LoC, Level of Confidence regarding diagnosis; MRI, Magnetic Resonance Imaging; SpA, Spondyloarthritis.

At two-year follow-up the LoC in the group with an axSpA diagnosis at 2 years only was much lower than in the other two groups. In the group that only had an axSpA diagnosis at baseline, the LoC regarding the diagnosis increased most compared to baseline: physicians were more certain of the diagnosis no axSpA at two-year follow-up than they were of the diagnosis axSpA at baseline.

The number of patients with sacroiliitis on radiographs and MRI was much higher in the group with a consistent diagnosis of axSpA. Although the percentage of patients with sacroiliitis on MRI increased in the group with a diagnosis of axSpA at two-year follow-up only, this was still much lower $(21 \%)$ compared to the patients with a consistent diagnosis $(81 \%)$. This was in line with a low LoC in this group.

Conclusion: In a cohort of patients with CBP suspected of axSpA the diagnostic consistency rate was high. Interestingly, in the group that only had a diagnosis axSpA at baseline, rheumatologists were more certain about the absence of axSpA at two years than the presence of axSpA at baseline.

REFERENCES:

[1] Rudwaleit et al. (2004). How to diagnose axial spondyloarthritis early. Ann Rheum Dis

Disclosure of Interests: None declared

DOI: 10.1136/annrheumdis-2021-eular.349

\section{OP0051 LOOKING BEYOND BASDAI TOTAL SCORES: ANALYSIS OF THE BASDAI ON THE BASIS OF SEX}

S. Maguire ${ }^{1,2}$, P. Gallagher ${ }^{3}$, F. B. O'shea ${ }^{1,2} .{ }^{1}$ St James' Hospital, Department of Rheumatology, Dublin, Ireland; ${ }^{2}$ Trinity College Dublin, School of Medicine, Dublin, Ireland; ${ }^{3}$ St Vincent's Hospital, Department of Rheumatology, Dublin, Ireland

Background: Females with axial spondyloarthropathy (axSpA) average scores on patient reported outcomes (PROs) than males. However, this does not necessarily correlate to worse clinical findings. The Ankylosing Spondylitis Registry of Ireland (ARSI) is a national registry on patients with axSpA in Ireland and a source of epidemiological data.

Objectives: The purpose of this study was to compare the scores of each sex across the individual components of the BASDAI to understand why females report worse scores than males.

Methods: Analysis of the ASRI was preformed using IBM SPSS version 26. Patients were analyzed on the basis of gender. Comparison of baseline characteristics and mean BASMI, BASFI, HAQ and ASQoL were tested for significance using an independent two tailed t-test and a Mann Whitney $U$ test. Mean total BASDAI score and mean score for each component of the BASDAl were compared and tested for significance with the same statistical tests. A chi-squared test for independence was used to determine significance in variation of HLAB27 status and radiographic findings.

Results: A total of 857 patients were included in the analysis. Patient population was $24.9 \%$ (213) female and $75.1 \%$ (644) male with a mean age of 45.9 years and mean disease duration of 19.4 years (means: BASDAI 4.02, BASMI 4 BASFI 3.67, HAQ 0.53, ASQoL 6.48). Females had worse BASDAI(4.6 vs 3.83 $\mathrm{p}<0.01), \mathrm{HAQ}(0.6$ vs $0.51, \mathrm{p}=0.03$ ) and $A S Q$ oL scores (7.62 vs $6.12, \mathrm{p}<0.01$ ) than males. BASFI scores were worse in females which did not reach significance (3.89 vs $3.63, p=0.26$ ). However, females had significantly better BASMI scores than males ( 3.51 vs $4.16, p<0.01$ ). Within the BASDAI, females scored significantly worse than males across all components (Fatigue: 5.56 vs $4.51, p<0.01$ Spinal pain: 5.51 vs 4.63, $p<0.01$; Other pain: 3.82 vs 3.19, $p=0.01$; Discomfort 4.05 vs $3.29, p<0.01$; EMS: 4.55 vs $3.94, p=0.01$ ), however duration of EMS did not reach significance (3.54 vs $3.12, \mathrm{p}=0.07$ ) (graph 1 ). Within the BASDAI, females recorded highest mean scores for fatigue (5.56), while males recorded highest mean scores for spinal pain(4.63). Lowest mean scores for both genders was for EMS duration (3.54 vs 3.12). Ranking of the BASDAI components by mean scores show similarity in the ranking of discomfort, EMS, other pain and EMS duration(Table 1).

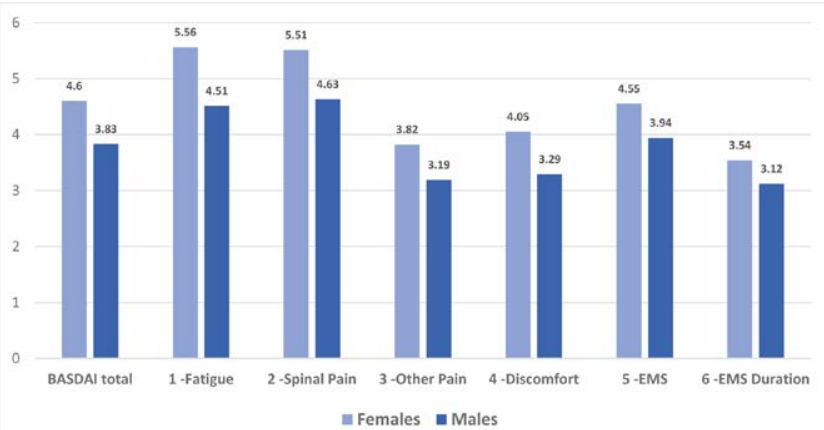

Graph 1. Breakdown of BASDAI scores in Females compared to Males

Table 1. Ranking in order of severity by mean score

\begin{tabular}{ccc}
\hline & Females & Males \\
\hline $\mathbf{1}$-most severe & Fatigue & Spinal pain \\
$\mathbf{2}$ & Spinal Pain & Fatigue \\
$\mathbf{3}$ & EMS & EMS \\
$\mathbf{4}$ & Discomfort & Discomfort \\
$\mathbf{5}$ & Other pain & Other pain \\
$\mathbf{6}$-least severe & EMS duration & EMS duration \\
\hline
\end{tabular}

Conclusion: AxSpA females have consistently worse PROs but have better spinal mobility than males. Despite females recording worse BASDAI scores than males, the pattern of active disease is similar in 4 of the 6 components of the BASDAI. However, fatigue is the most problematic symptom in females with active axSpA while spinal pain is the most problematic symptom for males. This variation by gender should be kept in consideration when evaluating a patient with suspected active axSpA.

References:

Disclosure of Interests: Sinead Maguire Grant/research support from: Recipient of the Gilead Inflammation Fellowship, Phil Gallagher: None declared, Finbar Barry O'Shea: None declared

DOI: 10.1136/annrheumdis-2021-eular.633

\begin{tabular}{l|l}
\hline OP0052 & FACTORS ASSOCIATED WITH REMISSION AT 5 \\
YEARS OF FOLLOW-UP IN EARLY ONSET AXIAL \\
SPONDYLOARTHRITIS: RESULTS FROM THE DESIR \\
COHORT
\end{tabular}

L. Pina Vegas ${ }^{1,2}$, E. Sbidian ${ }^{1,3,4}$, D. Wendling ${ }^{5,6}$, P. Goupille ${ }^{7}$, S. Ferkal ${ }^{3,4}$, P. Le Corvoisier $^{4,8}$, B. Ghaleh ${ }^{9}$, A. Luciani ${ }^{10}$, P. Claudepierre ${ }^{1,2}$. ${ }^{1}$ Université Paris Est Créteil, EpiDermE, Créteil, France; ${ }^{2}$ Hôpital Henri Mondor, Rhumatologie, Créteil, France; ${ }^{3} \mathrm{Hoppital}$ Henri Mondor, Dermatologie, Créteil, France; ${ }^{4} \mathrm{Hôpital} \mathrm{Henri}$ Mondor, INSERM, Centre d'Investigation Clinique 1430, Créteil, France; ${ }^{5} \mathrm{CHRU}$ de Besançon, Rhumatologie, Besançon, France; ${ }^{6}$ Université de Franche-Comté, EA 4266 "Agents pathogènes et inflammation », Besançon, France $;{ }^{7} \mathrm{CHU}$ de Tours, Rhumatologie, Tours, France; ${ }^{8}$ Université Paris Est Créteil, Ecole Nationale 
Vétérinaire d’Alfort, Inserm, U955-IMRB, Équipe 03, Créteil, France; ${ }^{9}$ Université Paris Est Créteil, INSERM, U955 équipe 03, Créteil, France; ${ }^{10}$ Université Paris Est Créteil, INSERM, U955 équipe 18, Créteil, France

Background: The disease course of axial $\mathrm{SpA}(\mathrm{axSpA})$ is highly variable and can be characterized by ongoing axial inflammation and radiographic progression associated with restricted mobility of the spine, reduced function and disability leading to impairment in quality of life. Control of disease activity is a primary aim in axSpA management. To assess disease activity the Ankylosing Spondylitis Disease Activity Score-C-reactive protein (ASDAS-CRP) is often considered as a reference tool. The data on remission are spare in axSpA and the identification of long-term remission factors, enabling the patient's management to be adapted, seems necessary but remains unclear.

Objectives: To evaluate the proportion of patients in remission according to ASDAS-CRP at 5 years of follow-up, to describe their characteristics in comparison with patients with active disease at that time, and to identify baseline factors associated with remission at 5 years of follow-up.

Methods: We included all patients from the DESIR (Devenir des Spondylarthropathies Indifférenciées Récentes) cohort with available data on ASDAS-CRP at 5-year follow-up and TNF $\alpha$ inhibitors exposure. Patients in remission, defined as an ASDAS$\mathrm{CRP}<1.3$, and with active disease were compared according to their main demographic, clinical, biological and radiological characteristics. A logistic model stratified on TNF $\alpha$ inhibitors exposure was used in the main analysis. Sensitivity analyses among patients with axSpA diagnosis confirmed by rheumatologist at 5-years were performed. Results: A total of 614 patients were followed in the DESIR cohort at M60. After excluding those with missing data on ASDAS score $(n=163)$ and TNF $\alpha$ inhibitors exposure $(n=2)$, analyzed patients were $449(73 \%)$. Excluded patients had similar baseline characteristics to those included in the analysis. Among patients unexposed to TNF $\alpha$ inhibitors ( $n=247), 77$ (31\%) were in remission $(37,8 \pm 8,3$ years; $55 \%$ men, 58\% NSAID users), 170 (69\%) weren't (39,8 $\pm 8,6$ years; $42 \%$ men, $81 \%$ NSAID users). Among exposed patients $(n=202), 34(17 \%)$ were in remission $(36,1 \pm 8,1$ years; $71 \%$ men, $29 \%$ NSAID users), $168(83 \%)$ weren't $(39,5 \pm 9,0$ years; $41 \%$ men, $63 \%$ NSAID users) (Figure 1$)$. Overall, patients in remission were more frequently men, $\mathrm{HLA}-\mathrm{B} 27+$, with high education and lower $\mathrm{BMI}$ at 5 -year of follow-up. The baseline factors associated with remission at 5 years of follow-up from the multivariate analysis are presented in Table 1.

Table 1. Baseline factors associated with remission at 5-year follow-up (multivariate analysis)

\begin{tabular}{|c|c|c|}
\hline & $\begin{array}{l}\text { Baseline factors positively associated with } \\
\text { 5-year remission }\end{array}$ & $\begin{array}{l}\text { Baseline factors negatively associated with } \\
\text { 5-year remission }\end{array}$ \\
\hline $\begin{array}{l}\text { Unexposed to } \\
\text { TNFa inhibitors }\end{array}$ & $\begin{array}{l}\text { - Past history of arthritis }\left(\mathrm{OR}_{\mathrm{a}}=2.1,95 \% \mathrm{Cl}\right. \\
1.2-5.3)\end{array}$ & - LOW BASDAI (OR $=0.9,95 \% \mathrm{Cl} 0.8-0.9)$ \\
\hline $\begin{array}{l}\text { Exposed to } \\
\text { TNFa inhibitors }\end{array}$ & - High education $\left(\mathrm{OR}_{\mathrm{a}}=2.9,95 \% \mathrm{Cl} 1.6-5.1\right)$ & $\begin{array}{l}\text { - Low BASDAI }\left(\mathrm{OR}_{\mathrm{a}}=0.9,95 \% \mathrm{Cl} 0.9-0.9\right) \\
\text { - Low BMI }\left(\mathrm{OR}_{\mathrm{a}}=0.8,95 \% \mathrm{Cl} 0.7-0.9\right) \\
\text { - Low enthesitic index }\left(\mathrm{OR}_{\mathrm{a}}=0.8, \mathrm{IC} 95 \% 0.7 \text { - }\right. \\
\text { 0.9) }\end{array}$ \\
\hline
\end{tabular}

TNF $\alpha$ : Tumor Necrosis Factor alpha; OR : adjusted Odd Ratio; 95\%IC: 95\% confidence interval; BASDAI: Bath Ankylosing Spondylitis Disease Activity Index; BMI: Body Mass Index.

Conclusion: The overall remission rate at 5 years was 25\%, 31\% among patients unexposed to TNF $\alpha$ inhibitors and $17 \%$ among those exposed. This study reveals the difficulty in achieving 5-year remission in recent axSpA, especially in the most active forms at baseline; socio-educational factors and overweight also appear to be related. Acknowledgements: L Pina Vegas received a Master 2 grant from the French Society of Rheumatology (Bourse Master 2ème Année 2019)

Disclosure of Interests: Laura Pina Vegas: None declared, Emilie Sbidian: None declared, Daniel Wendling: None declared, Philippe Goupille: None declared, Salah Ferkal: None declared, Philippe Le Corvoisier: None declared, Bijan Ghaleh: None declared, Alain Luciani: None declared, Pascal Claudepierre Speakers bureau: Abbvie, Janssen, Lilly, MSD, Novartis, Pfizer, Consultant of: Abbvie, Pfizer, Roche-Chugai, Bristol-Myers Squibb, MSD, UCB, Novartis, Janssen, Lilly, Celgene (consulting fees, less than 10,000 \$ each)., Employee of: Roche Chugai, Sanofi Aventis, Celgene, Pfizer, MSD, Novartis and BMS (investigator). DOI: 10.1136/annrheumdis-2021-eular.305

\begin{tabular}{l|l}
\hline OP0053 & IMPACT OF CORRECTING CRP THRESHOLD \\
ACCORDING TO BMI ON DIAGNOSIS, DISEASE \\
ACTIVITY, INDICATION OF BIOLOGICAL \\
TREATMENT AND PREDICTION OF THERAPEUTIC \\
RESPONSE, IN PATIENTS SUSPECTED OF AXIAL \\
SPONDYLOARTHRITIS. RESULTS FROM DESIR COHORT
\end{tabular}

O. Facorat ${ }^{1}$, J. Morel ${ }^{2}$, B. Combe ${ }^{2}$, P. Richette ${ }^{3}$, C. Lukas ${ }^{2} .{ }^{1}$ University Hospital of Martinique, Rheumatology, Fort de France, France; ${ }^{2}$ University Hospital of Montpellier, Rheumatology, Montpellier, France; ${ }^{3}$ Lariboisière Hospital, Rheumatology, Paris, France
Background: Acute phase reactants are crucial parameters to consider for management of chronic inflammatory back pain (IBP) patients suspect of axial spondyloarthritis (ax-SpA). Indeed, C-reactive protein (CRP) is part of ASAS classification criteria for SpA, impacts on assessment of disease activity by ASDASCRP score, and should be elevated when a bDMARD is discussed in patients without radiological sacroiliac lesions. Moreover, elevated CRP is regarded predictive of favorable therapeutic response. Obesity in otherwise healthy people is associated with high CRP values. An adjusted definition of normal CRP threshold based on gender and BMI has been proposed.

Objectives: The aim of this study was to assess whether correcting CRP threshold with patient's BMI would change classification according to ASAS criteria for ax-SpA, presence of clinically relevant activity according to ASDAS-CRP, indication for TNF inhibitor (TNFi) and, as primary endpoint, improve prediction of therapeutic response to first TNFi.

Methods: The study was conducted in DESIR cohort, which included 708 patients with early IBP suspect of ax-SpA. We included all patients with available data on BMI and CRP. High CRP level was defined either according to usual threshold $(5 \mathrm{mg} / \mathrm{L})$ or to the formula using BMI for adjustment. With this formula CRP could be considered "normal" or due to obesity if: $\leq 1+(\mathrm{BMI}-25) / 25$ for men and $\leq 1+(\mathrm{BMl}-25) / 12.5$ for women (with CRP in $\mathrm{mg} / \mathrm{dL}$ ). We reported distribution of CRP levels in patients with high level according to usual threshold but below $\mathrm{BMI}$ adjusted threshold, as it is potentially suggestive of false-positive CRP due to overweight/obesity. Among them, we identified those who had no objective sign of disease activity (defined as arthritis, dactylitis, active uveitis or inflammatory bowel disease). To evaluate the impact on classification/diagnosis, we examined HLAB27-positive patients with only 2 ASAS criteria, including high CRP (the second being IBP, since it was mandatory for inclusion in DESIR cohort). Then, we calculated ASDAS-CRP score. We presented proportions of patients with ASDAS high or very high disease activity but high CRP level possibly due to BMI only, and among those, the number concerned by a change of disease activity level when adjusting ASDAS-CRP score with minimal value for CRP (2mg/l). Among patients treated by TNFi during first 24-month follow-up, we excluded those with sacro-iliitis, and studied in others, CRP levels at last visit before treatment initiation using both thresholds. We compared proportion of ASAS40 responders using logistic regression analysis, with abnormal CRP defined after correction for BMI in patients without any sign of activity, beside other classical predictive factor of therapeutic response (age, gender, sacro-iliitis, HLAB27, psoriasis, arthritis, smoking) Results: Data were available for 634 patients. 205 had a high CRP level using usual threshold, of which 73 (35.6\%) had a high CRP possibly due to BMI alone as they had no objective sign of disease activity. There were no differences in diagnosis as no patient had as only ASAS criteria: HLAB27 associated with high CRP and IBP. ASDAS-CRP score could be calculated in 626 patients. By correcting ASDAS score for patients with high CRP possibly due to BMI, 95.3\% remained with same activity level (kappa for the ASDAS levels was 0.93). For impact of CRP on indication of bDMARD, 178 patients were treated by TNFi during first 24 months of follow-up: $61 \%$ of patients had an indication of TNFi according to EMA, with usua CRP threshold, and $56 \%$ with the adjusted one. Regarding response to TNFi, there were no association between any of the 2 CRP thresholds and ASAS40 response. Only sacro-iliitis on MRI was associated with ASAS40 response.

Conclusion: Adjustment of CRP threshold according to BMI has a very limited impact on diagnosis, evaluation of disease activity of $\mathrm{SpA}$, indication of TNFi initiation and prediction of TNFi response.

Disclosure of Interests: Odile Facorat: None declared, Jacques Morel Speakers bureau: Abbvie, Biogen, BMS, Fresenius Kabi, Lilly, Mylan, Novartis, Pfizer, Sanofi, Consultant of: Abbvie, BMS, Boerhinger Ingelheim, Galpaagos, GSK, Lilly, Novartis, Sanofi, Grant/research support from: Biogen, BMS, Lilly, Novartis, Pfizer, Sanofi, Servier, Bernard Combe Speakers bureau: AbbVie; Bristol-Myers Squibb; Gilead; Janssen; Lilly; Merck; Novartis; Pfizer; Roche-Chugai; and Sanofi, Consultant of: AbbVie; Bristol-Myers Squibb; Gilead; Janssen; Lilly; Merck; Novartis; Pfizer; Roche-Chugai; and Sanofi, Grant/research support from: Novartis, Pfizer, and Roche-Chugai, Pascal Richette Consultant of: AbbVie, Amgen, Biogen, BMS, Celgene, Janssen-Cilag, Lilly, Medac, MSD, NORDIC Pharma, Novartis, Pfizer, Roche, SanofiAventis, UCB, Cédric Lukas Speakers bureau: Abbvie, Amgen, Janssen, Lilly, MSD, Novartis, Pfizer, RocheChugai, UCB, Consultant of: Abbvie, Amgen, Janssen, Lilly, MSD, Novartis, Pfizer, Roche-Chugai, UCB, Grant/research support from: Pfizer, Novartis and Roche-Chuga DOI: 10.1136/annrheumdis-2021-eular.609

\section{Vasculitis -}

OP0054

NEW ROLE FOR PROTEINASE 3 IN IL-16 BIOACTIVITY CONTROL IN GRANULOMATOSIS WITH POLYANGIITIS

A. Kerstein-Staehle ${ }^{1}$, C. Alarcin ${ }^{1}$, J. Luo ${ }^{1}$, G. Riemekasten ${ }^{1}$, P. Lamprecht ${ }^{1}$, A. Müller ${ }^{1}{ }^{1}$ University of Luebeck, Department of Rheumatology and Clinical Immunology, Lübeck, Germany 